\title{
Unusual Presentations of Tuberculosis: A Case Series
}

\author{
Mano Raj Dayalan ${ }^{*}$, Hema Darshinee Johnson', Ganesh Kasinathan ${ }^{2}$, Naganathan Pillai ${ }^{1}$ \\ ${ }^{1}$ Monash University Malaysia, Johor Bahru, Johor, Malaysia \\ ${ }^{2}$ Department of Medicine, Segamat Hospital, Johor, Malaysia \\ Email: "manorajdayalan@gmail.com
}

Received 16 February 2016; accepted 2 March 2016; published 7 March 2016

Copyright (C) 2016 by authors and OALib.

This work is licensed under the Creative Commons Attribution International License (CC BY). http://creativecommons.org/licenses/by/4.0/

(c) (i) Open Access

\begin{abstract}
Introduction: Tuberculosis (TB) is an air-borne infection caused by the organism Mycobacterium Tuberculosis that can affect any organ though it commonly involves infection of the lungs. Given the nature of Extra-Pulmonary Tuberculosis (EPTB) that has various form of clinical manifestation, diagnosing EPTB remains a challenge. Background: This report discusses three cases of EPTB that posed diagnostic and management challenges. The first case presented as pleural effusion and TB was diagnosed on pleural biopsy. The second case presented with abdominal pain and mass in the right iliac fossa. Final diagnosis of tuberculous colitis was made post-laparotomy and he underwent successful anti-tuberculous treatment. The third case presented with a single enlarged cervical lymph node and a typical history. Investigations were suggestive of tuberculous lymphadenitis and patient showed a positive response to anti-tuberculous treatment. Conclusion: EPTB has various forms of clinical manifestation, which imposes diagnostic and treatment challenges. Thus, it is crucial to always include tuberculosis as part of working diagnosis especially in regions where tuberculosis is endemic until proven otherwise. Hence it is imperative to start treatment early to ensure better response.
\end{abstract}

\section{Keywords}

Extra-Pulmonary Tuberculosis, Pleural Effusion, Colitis, Lymphadenitis

Subject Areas: Infectious Diseases

\section{Introduction}

Tuberculosis (TB) is an air-borne infection caused by the organism Mycobacterium Tuberculosis which can affect any organ though it commonly involves infection of the lungs [1]. TB is further classified into Pulmonary

${ }^{*}$ Corresponding author.

How to cite this paper: Dayalan, M.R., Johnson, H.D., Kasinathan, G. and Pillai, N. (2016) Unusual Presentations of Tuberculosis: A Case Series. Open Access Library Journal, 3: e2478. http://dx.doi.org/10.4236/oalib.1102478 
Tuberculosis (PTB) and Extra-Pulmonary Tuberculosis (EPTB) based on the site of infection as per the name suggests. EPTB makes up at least 20\% of TB cases worldwide [2]. Although the most common site of infection of EPTB is lymph node, other sites of infection include pleura, urogenital tract, bones and joints, meninges, central nervous system, bowel and/or peritoneum, pericardium, and skin [3]. Studies conducted in Netherlands and United States have established that EPTB commonly affects women, ethnic minorities and foreigners [4]. In addition, various studies have proven that immunocompromised status especially having retroviral disease along with other less common factors like diabetes mellitus, malnourishment, extremes of age groups and prolonged chemotherapy or steroid treatment are frequently associated with EPTB infection [5] [6]. Despite having significant risk factors, an effective algorithm in identifying, diagnosing and managing EPTB still remains a challenge. This is mainly contributed by the nature of EPTB that could mimic other common pathologies [7] [8]. Besides that, various clinical manifestation of EPTB imposes difficulties in obtaining relevant sample of specimen for diagnostic purposes [9]. Thus, EPTB remains a challenging diagnosis given its dependency on a very high clinical suspicion. Besides that, varying clinical expertise of the clinicians, limited access to diagnostic measures and a lack of experience in managing EPTB impose great limitations in diagnosing and treating EPTB.

\section{Case Presentation}

\subsection{Case 1: Tuberculosis of the Pleura}

The first case presentation is based on a 22 years old male of Malay descent, a contractor who presented to the hospital with a three day history of non-productive cough associated with right sided pleuritic chest pain and high fever associated with chills and rigors. However he denied any hemoptysis. With regards to his fever, it had been consistently high over the three days that worsened at night as well. He denied having night sweats. In addition, he also experienced headache and fatigue. However, he had no previous medical or surgical history. He is not currently on any medication. He had no history of smoking, alcohol use or any form of illicit drug abuse. The patient had no recent history of travel but had been in consistent contact with foreign workers from Bangladesh, Indonesia and Nepal. Besides that, he had history of tuberculosis patient contact with his sister three weeks prior to presentation.

Upon physical examination, he was febrile at a temperature of $39.4^{\circ} \mathrm{C}$. On examination of the chest, there was an obvious reduction of chest wall expansion on the right side. Percussion note revealed stony dullness on right lower zone of the lung. Upon auscultation, air entry was absent on the right lower zone.

Further investigations (refer Table 1) revealed mildly elevated white blood cell count and a high erythrocyte sedimentation rate. Sputum smear results were negative for acid-fast bacilli and sputum culture revealed no growth. A chest X-Ray (refer Image 1) revealed a right-sided pleural effusion, which was followed by pleurocentesis and pleural biopsy. The pleural fluid smear and culture results were both negative. Pleural fluid biochemistry on the other hand revealed an exudative effusion (refer Table 2). Histopathological examination of the pleural biopsy was reported as granulomatous inflammation and thus raised a high suspicion of tuberculosis given that the patient did not respond to initial treatment of intravenous Ceftriaxone 2grams once daily for seven days (choice and dosage of antibiotics were adopted from the National Antibiotics Guidelines 2014, Malaysia) .

Thus, patient was diagnosed with tuberculosis of pleura. He was started on standard anti-tuberculous treatment which consisted of two months of intensive therapy followed by 7 months of maintenance therapy. He was treated with four oral drugs during the intensive phase which were isoniazid, rifampicin, ethambutol and pyrazinamide. The maintenance phase of treatment incorporated two oral drugs which were isoniazid and rifampicin.Oral pyridoxine supplementation was given throughout the treatment course to prevent the development of isoniazid induced peripheral neuropathy. At the end of his treatment, patient completely recovered from his clinical symptoms and has gained weight from $56 \mathrm{~kg}$ to $63 \mathrm{~kg}$. His post treatment chest X-Ray showed clear lung fields with right lower subpleural thickening (Image 2).

\subsection{Case 2: Tuberculous Colitis}

A 64-year-old male of Chinese descent presented with a history of loss of weight, loss of appetite and low-grade fever of uncertain duration. He however did not experience any altered bowel habits or haematochezia. There were no significant risk factors. In addition, patient was a non-smoker although he consumed alcohol occasionally. He did not have any significant family or past medical history. Besides, there was no recent travel history or contact with tuberculosis patients. 


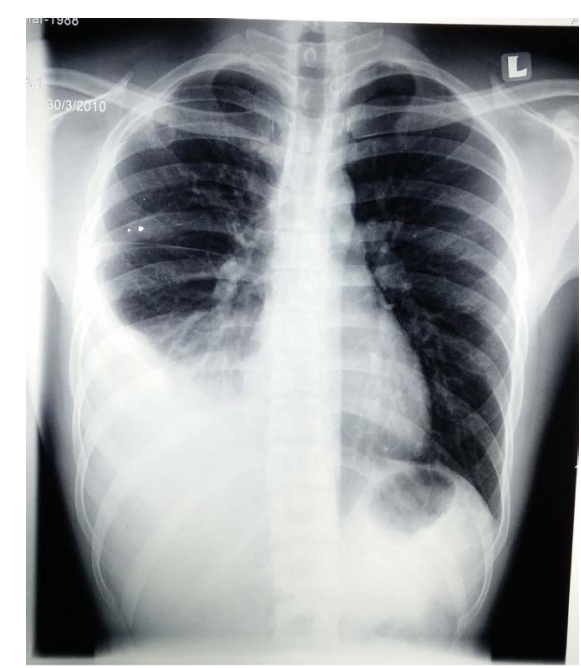

Image 1. Chest X-Ray at presentation (before treatment) shows right sided pleural effusion.

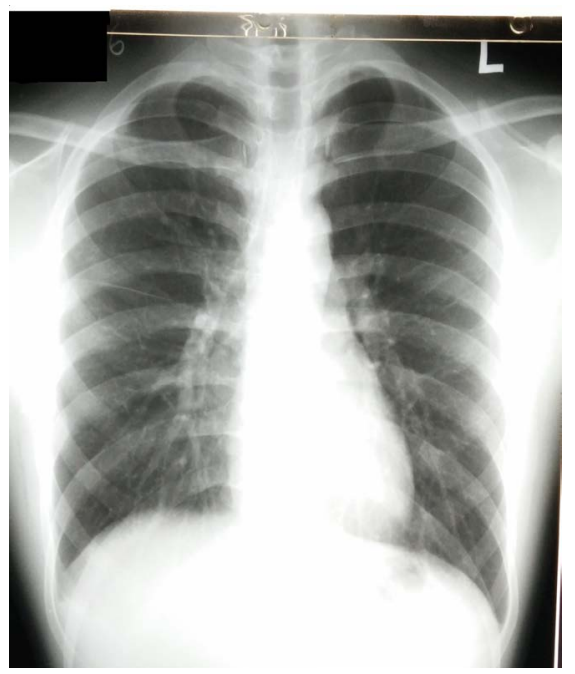

Image 2. Chest X-Ray post completion of treatment shows resolution of right sided pleural effusion with right lower subpleural thickening.

Table 1. Blood investigations.

\begin{tabular}{cc}
\hline Parameters & Values \\
Haemoglobin & $14.7 \mathrm{~g} / \mathrm{dL}$ \\
Total White Cell & $11 \times 10^{9} / \mathrm{L}$ \\
Platelet & $353 \times 10^{9} / \mathrm{L}$ \\
ESR & $62 \mathrm{~mm} / \mathrm{hr}(\mathrm{raised})$ \\
Urea & $3.8 \mathrm{mmol} / \mathrm{L}$ \\
Creatinine & 89 umol $/ \mathrm{L}$ \\
AST & $27 \mathrm{U} / \mathrm{L}$ \\
HIV & Non reactive \\
Hep B & Non reactive \\
Hep C & Non reactive \\
\hline
\end{tabular}


Table 2. Pleural fluid analysis.

\begin{tabular}{cc}
\hline Parameters & Values (normal) \\
Total Protein & $59 \mathrm{~g} / \mathrm{l}$ (pleural:serum Total protein $>0.5$ ) \\
Lactate Dehyrogenase & $1220 \mathrm{U} / \mathrm{L}$ (pleural:serum LDH ratio $>0.6$ ) \\
Glucose & $4.5 \mathrm{mmol} / \mathrm{L}$ \\
Amylase & $37 \mathrm{U} / \mathrm{L}$ \\
Urea & $3 \mathrm{mmol} / \mathrm{L}$ \\
Creatinine & $73 \mathrm{umol} / \mathrm{L}$ \\
Albumin & $34 \mathrm{~g} / \mathrm{L}$ \\
Culture & No growth \\
\hline
\end{tabular}

Upon physical examination, patient's vital signs were stable. His significant examination findings included mildly distended abdomen with a positive fluid shift but negative fluid thrill. A localized mass was palpable in the right iliac fossa, which was tender on palpation.

The blood parameters are as shown in Table 3. Further, peritoneal fluid was tapped and analyzed; findings include scattered mesothelial cells and abundant inflammatory cells predominantly polymorphs, lymphocytes and histiocytes, which were highly suggestive of inflammatory yield. However, malignant cells were not observed. A colonoscopy was then performed at a different center (refer Image 3) and the macroscopic appearance of the lesion was suggestive of a tumor and biopsied.

Thus, patient underwent an exploratory laparotomy and a right-hemicolectomy was performed. The specimen was sent for further histopathology examination, which showed granulomatous enterocolitis and epitheloid histocytes, multinucleated Langhan's type giant cells, lymphocytes and fibrosis.

This led to a suspicion of tuberculous colitis and thus patient was started on anti-tuberculosis treatment which consisted of two months of intensive therapy followed by seven months of maintenance treatment. During the two months of intensive phase, he was given four oral drugs which were isoniazid, rifampicin, ethambutol and pyrazinamide. The seven month maintenance phase consisted of oral isoniazid and rifampicin. Oral pyridoxine supplementation was added throughout the course of treatment to prevent isoniazid induced peripheral neuropathy. Patient showed improvement of clinical symptoms including progressive weight gain upon commencement of anti-tuberculosis treatment which was completed over a duration of nine months.

\subsection{Case 3: Tuberculous Cervical Lymphadenitis}

A 40-year-old female patient presented to the local general practitioner clinic complaining of swelling on her right side of the neck for 1 month. This was associated with loss of appetite, loss of weight and night sweats. However she did not experience any episodes of fever or prolonged cough although she had positive tuberculosis contact history. She has a background history of type 2 diabetes mellitus, for which she is on oral anti-diabetic medication. She is a non-smoker and has no history of illicit drug use or alcohol consumption.

Upon physical examination, patient was comfortable and alert. She was afebrile. Significant findings included an enlarged right cervical lymph node. This measured to approximately $1 \mathrm{~cm} \times 1 \mathrm{~cm}$, non-tender upon palpation, and appeared matted.

The blood investigations are as shown in Table 4. Her ESR upon presentation to the GP was raised at 110 $\mathrm{mm} / \mathrm{hr}$ with normal full blood examination parameters except for her monocyte count, which was raised at $13 \%$. Her chest X-ray was normal. The tuberculin skin test was raised to $25 \mathrm{~mm}$ at 72 hours. She was then started on standard anti-tuberculous medications which consisted of two months of intensive therapy incorporating four oral drugs which were isoniazid, rifampicin, ethambutol and pyrazinamide. The maintenance treatment consisted of seven month therapy of two oral drugs which were isoniazid and rifampicin. Oral pyridoxine supplementation was added throughout the course of treatment. Symptomatic improvement was noticed in the first month with significant weight gain, better appetite and she stopped having night sweats. The lymph node remained same in size after the first month of treatment. There were no new enlarged lymph nodes. 

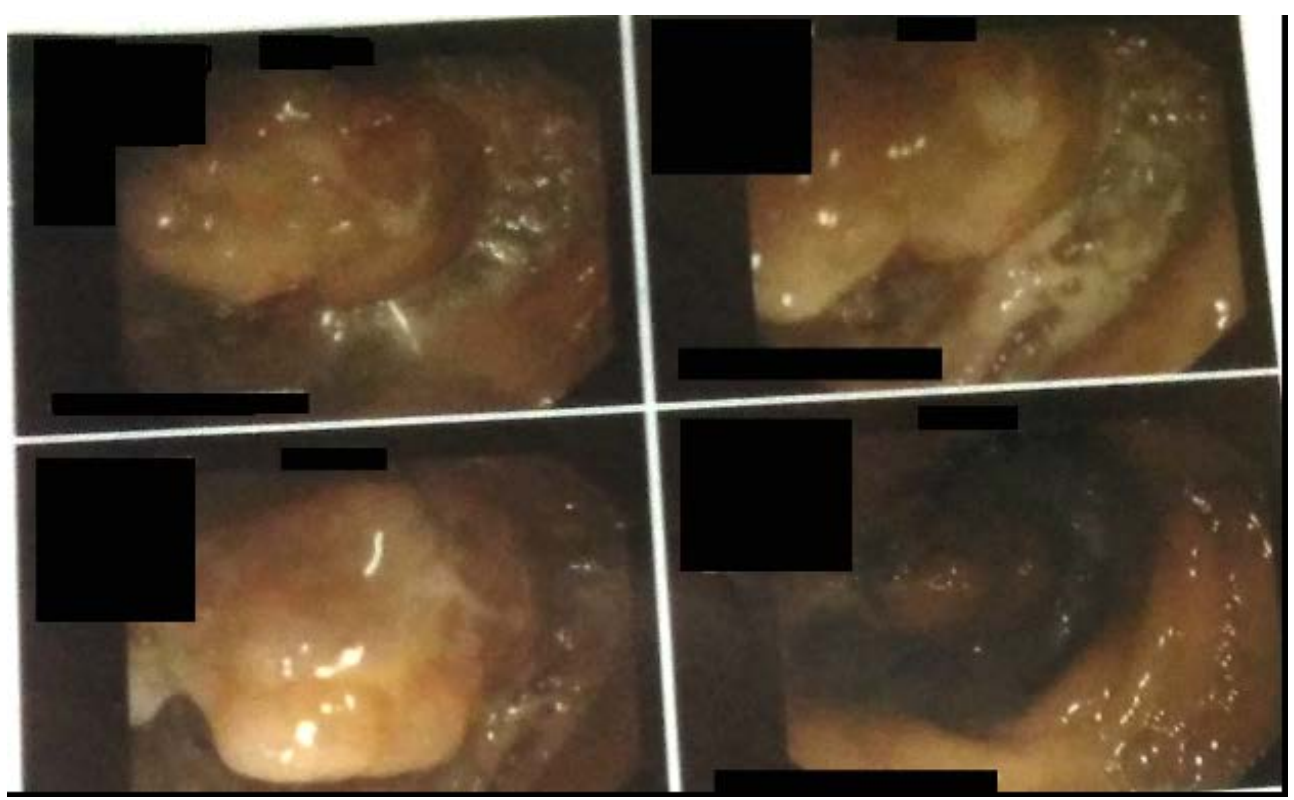

Image 3. A mass lesion on lower end of ascending colon on colonoscopy.

Table 3. Investigation findings.

\begin{tabular}{cc}
\hline Parameters & Values \\
Haemoglobin & $14.0 \mathrm{~g} / \mathrm{dL}$ \\
Red Blood Cell Count & $5.1 \times 10^{6} / \mathrm{ml}$ \\
Platelet Count & $500 \times 10^{9} / \mathrm{L}$ \\
Erythrocyte Sedimentation Rate (ESR) & $39 \mathrm{~mm} / \mathrm{hr}$ \\
Total White Cell Count & $5.0 \times 10^{9} / \mathrm{L}$ \\
Urea & $2.0 \mathrm{mmol} / \mathrm{L}$ \\
Creatinine & $61 \mathrm{micromol} / \mathrm{L}$ \\
Total protein & $67 \mathrm{~g} / \mathrm{L}$ \\
Albumin & $31 \mathrm{~g} / \mathrm{L}$ \\
ALT & $18 \mathrm{U} / \mathrm{L}$ \\
AST & $19 \mathrm{U} / \mathrm{L}$ \\
Alkaline Phosphatase & $72 \mathrm{U} / \mathrm{L}$ \\
\hline
\end{tabular}

\section{Discussion}

\subsection{Tuberculous Pleural Effusion}

Tuberculous pleural effusion is an accumulation of fluid at pleural space due to a delayed hypersensitivity reaction that is either a manifestation of a primary Mycobacterium Tuberculosis infection or secondary to reactivation of the disease. Tuberculous pleural effusion being the second most common type of extra pulmonary tuberculosis makes up 5\% of the total Mycobacterium Tuberculosis infection [10]. The incidence of tuberculous pleural effusion however, varied from $4 \%$ in United States to $23 \%$ in Spain despite a higher frequency of Tuberculosis patient in the Asian continent [11] [12].

The pathogenesis of tuberculous pleural effusion is initiated by the rupture of subpleural caseous focus of the lung into the pleural space [13]. This is followed by hypersensitivity reaction mediated by predominantly CD4 T 


\begin{tabular}{cc} 
Table 4. Blood investigations. & \\
\hline Parameters & Values \\
\hline Haemoglobin & $11.3 \mathrm{~g} / \mathrm{dl}$ \\
Red Blood Cell Count & $4.0 \times 10^{6} / \mathrm{ml}$ \\
Haem Indices ( PCV, MCV, MCH, MCHC) & PCV 35\% \\
& MCV $88 \mathrm{fl}$ \\
Platelet Count & MCH $28 \mathrm{pg} / \mathrm{cell}$ \\
Erythrocyte Sedimentation Rate (ESR) & MCHC 32 \% \\
Total White Cell Count & $267 \times 10^{9} / \mathrm{L}$ \\
Differential Count & $110 \mathrm{~mm} / \mathrm{hr}$ \\
& $7.0 \times 10^{9} / \mathrm{L}$ \\
Peripheral Blood Film & Polymorphs $66 \%$ \\
& Lymphocytes $20 \%$ \\
& Monocytes $13 \%$ \\
& Eosinophils $1 \%$ \\
& Basophils $0 \%$ \\
\hline
\end{tabular}

helper lymphocytes that occurs approximately 6 - 12 weeks after the primary infection [14] [15]. As a consequence, the adenosine deaminase (ADA) and gamma-interferon will be markedly elevated in the tuberculous pleural fluid [16]. The accumulation of fluid in pleural space in primary disease is due to increase in permeability of the capillaries and occlusion of pleural stomata that impairs lymphatic clearance of protein and fluid in pleural space whereas in tuberculous pleural effusion secondary to reactivation of the disease, this is mainly associated with parenchymal damage [17] [18].

Thus, patients with tuberculous pleural infection usually present as acute illness with common clinical symptoms of non-productive cough, pleuritic chest pain and fever for less than one week [19] [20]. Previous studies have demonstrated that the mean age of primary tuberculous pleuritis is 28 years old whereas in secondary reactivation, the mean age is 54 years old [21]. However, a newer study has established a higher median age of 56 years old in all patients presenting with tuberculous pleuritis [22]. Thus, the diagnosis of pleural tuberculosis should be considered in any adult or elderly patient presenting with unilateral pleural effusion [23]. Besides that, the incidence of tuberculous pleural effusion is higher among patients with HIV positive although being a hypersensitivity reaction; the rate of pleural tuberculosis should be lower in immuno-compromised state [24]. However, a study has proven that tuberculous pleural effusion is more common in HIV patients with higher CD4+ counts [25]. Besides, HIV positive patients presenting with tuberculous pleuritis are usually older and have a higher incidence of disseminated disease [26].

Although tuberculous pleuritis may resolve spontaneously without aggressive treatment, studies have proven that subsequently, as much as $65 \%$ of tuberculous pleural effusion patients have developed some form of active tuberculosis regardless of the nature and severity of their initial presentation [27]. This emphasizes the need to diagnose and manage tuberculous pleural effusion effectively. A study in Malaysia has concluded that a good overall treatment outcome of pleural tuberculosis is determined by early detection of the disease and implementing measures to ensure high adherence rate [28]. Thus, the major challenge in managing pleural tuberculosis remains in effective diagnosis.

Firstly, the pleural fluid in tuberculosis infection is invariably an exudate where its protein levels are almost always more than $5 \mathrm{~g} / \mathrm{dL}$ and small lymphocytes makes up more than $50 \%$ of the content [20]. Besides that, if a patient presents within two weeks of infection, the pleural fluid would predominantly contain polymorphonuclear leucocytes [29]. Other than that, glucose of pleural fluid would either be lower or equivalent to the levels 
of glucose in serum whereas the LDH levels would be higher in pleural fluid [30]. Although the pH levels of pleural fluid maybe lower, in general the $\mathrm{pH}$ levels would be always higher than 7.30 [31]. In order to exclude tuberculosis as a differential diagnosis, although many studies have concluded that eosinophil levels are more than $10 \%$ will rule out tuberculosis infection, one study has articulated that this may not be the case anymore given that a Spanish study has established that $15.6 \%$ of eosinophilic pleural effusion in 45 patients was due to tuberculosis infection [31] [32]. Besides, this rule is also an exception in patients with pneumothrax or previous thoracocentesis as blood or air in the pleural space would invariably trigger eosinophilia [31] [32].

Various studies have conferred that one of the easiest and effective ways diagnosing tuberculous pleuritis is by demonstrating pleural fluid adenosine deaminase (ADA) level of more than $40 \mathrm{U} / \mathrm{L}$ and an elevated pleural fluid interferon gamma levels [33]. In fact, meta analysis has concluded that the combined specificity and sensitivity for pleural fluid ADA and interferon gamma levels in diagnosing tuberculosis pleural effusion is $93 \%$ and 96\% respectively [34]. A cost analysis study in India has established that pleural fluid interferon gamma levels are more sensitive compared to pleural ADA levels in diagnosing tuberculosis pleural effusion [35]. However, the same study has concluded that, the cost of performing this additional test in diagnosis one tuberculous pleuritis patient is equivalent to the cost of anti-tuberculosis treatment of six patients [28]. Thus, in developing countries where resources of medical treatment are limited, these tests may not be cost effective [35].

Other than that, sputum smear and culture that are routinely done to diagnose pulmonary tuberculosis is rather underutilized in diagnosing tuberculous pleural effusion [33]. Studies have shown that as many as 35 out of 64 pleural tuberculosis patients (55\%) whose sputum has been induced have positive sputum study despite having a clear chest X-Ray except for unilateral pleural effusion [36]. Although routine pleural fluid smear may not be useful, pleural fluid culture especially using BACTEC system has been proven to provide higher yields and faster results in diagnosing tuberculous pleural effusion [20] [37] [38]. Blind needle biopsy of the parietal pleura still is one of the effective method of diagnosing tuberculous pleural effusion [39]. Demonstrating granulomatous pleuritis on parietal pleural biopsy is sufficient to raise the suspicion of tuberculous pleural effusion as 95\% of granulomatous pleuritis is due to mycobacterium tuberculosis infection [39].

In terms of treating tuberculous pleurisy, a standard six-month treatment regimen is adequate in most of the cases [40]. This six month course is divided into 2 months of intensive treatment with isoniazid, rifampicin and pyrazinamide which followed by a four months of maintenance treatment with isoniazid and rifampicin only [41]. In countries where isoniazid resistance is prevalent, ethambutol or streptomycin should be added [42]. Other than that, surgical drainage, debridement, decortication and rib resection which used in treating patients with extensive pleuropulmonary disease is now rarely indicated except for thoracoscopy to make a definite diagnosis [40]. Besides that, another major concern is residual pleural thickening that occurs in at least $50 \%$ of patients, 6 - 12 months post-treatment especially in patients presented with loculated pleural effusion [43]. The use of fibrinolytic agent like urokinase has been proven to reduce residual pleural thickening [44]. Besides that, paradoxically worsening of pleural effusion upon commencement of treatment may occur which has been postulated to be due to isoniazid induced lupus pleuritis [45]. Some patients may also develop peripheral lung nodule, which will resolve upon completion of anti-tuberculous treatment [46]. Other than that, the role of corticosteroid is not indicated as studies have shown that there are no significant differences in patients treated with corticosteroid in terms clinical outcome, rate of absorption of pleural fluid, pleural sequelae and lung capacity at the end of treatment [47]. Besides that, although early drainage of pleural fluid confers better clinical treatment outcome, repeated drainage or complete drainage of pleural effusion does not confer any added advantages [48].

\subsection{Tuberculous Colitis}

On the other hand, tuberculous enteritis is tuberculous infection that can affect any part of the gastrointestinal tract though it commonly affects the ileocaecal junction [49]-[52]. Although tuberculous colitis is rather rare in developed countries, the incidence of such cases are on the rise for the past two decades where it accounts for up to $1 \%$ - 3\% of tuberculosis worldwide [49] [53]-[55]. Age, sex, socioeconomic status, immune status and Mycobacterium Tuberculosis genotype are major contributing factors towards a widely variable epidemiology of tuberculous colitis worldwide [56]. Studies have shown a predominance of female and young adults in regions with higher incidence of tuberculous colitis like Pakistan, Turkey, and West Africa [56]. However, in regions of lower incidence namely China, Singapore, India and the United Kingdom, such gender predominance is either equal or more towards male patients [56]. Besides that, studies have established immunocompromised status in 
particular retroviral disease as a strong risk factor for developing tuberculous colitis just like any other extrapulmonary tuberculosis in whole [57]. It is very important to note that tuberculous may mimic any gastrointestinal condition, which include Crohn's Disease and carcinoma of the colon and thus, impose great diagnostic challenges [57] [58].

The etiology of tuberculous enteritis is usually due to ingestion of bacterium; i.e. through food particles or bronchiole secretions in patients with existing pulmonary tuberculosis [55] [58]. Besides that, spread from adjacent organs or via haemotogenous spread is also another common etiology [59]. The terminal ileum particularly ileocaecal junction is the commonest site of infection tuberculosis which accounts for up to $90 \%$ of tuberculous colitis cases [50]-[52] [59]. The abundance of lymphoid tissue at terminal ileum, the stasis of intestinal content at the ileocaecal valve and the relatively longer transit time of intestinal contents with the mucosa at terminal region is the major contributory factors that facilitate the tuberculous infection at this region [60]-[63]. Besides that, tuberculous colitis less commonly affects ascending and descending colon as well [51].

Clinically, tuberculous colitis patients present with non-specific symptoms, which predominantly includes abdominal pain and weight loss [64]-[66]. Besides that, less than 50\% of 69 tuberculous patients in a study presented with fever, followed by per rectal bleed in $20 \%$ of patients and less commonly, abdominal mass was seen in only 6.4\% patients [59]. However, another study by Palmer et al. has shown up to $43 \%$ of tuberculous colitis patients presented with abdominal mass [67]. Various studies have also established that endoscopic features of tuberculosis of the colon is usually non-specific where it may show segmental ulcers, polyps, tumors, inflammatory stricture and rarely tuberculous colitis which could potentially mimic inflammatory bowel disease and malignancy of the colon [64] [66]-[69]. In addition, one retrospective review of 86 cases of tuberculous colitis showed $98 \%$ of participants with elevated ESR levels, $64 \%$ had microcytic anemia with reduction of albumin in $73 \%$ of patients [70]. Besides that, an estimated $15 \%$ - 20\% of patients with tuberculous colitis did not show any significant chest X-ray findings [51]. Thus, this explains the challenges in diagnosing tuberculous colitis.

Looking at evidences supporting more effective diagnostic measures of tuberculous colitis, Han et al studied tuberculous colitis cases using double-contrast barium enema and concluded that a finding of circular or transverse ulcer was more characteristic of tuberculous colitis [71]. Another study conducted in France established that in tuberculous colitis cases, the ileocaecel valve is usually rigid and incompetent while the caecum might be retracted [51] [72]. The study had also established that CT scan findings of tuberculous colitis involves asymmetrical and thickened wall of the colon which was in the presence of enlarged lymph node with a hypoattenuating centre which is a result of necrotic caseation [51] [72]. In addition, CT scan of the abdomen has shown to have a $67 \%$ of sensitivity in diagnosing tuberculous colitis [73]. In contrary, common diagnostic measure of demonstrating acid-fast bacilli or caseating granuloma on histological specimen has rather low sensitivity of 32\% and 50\% respectively [73]. In addition, the significance of mycobacterium tuberculosis culture and sensitivity in diagnosing tuberculous colitis is rather questionable given varying findings by previous studies [74]-[76]. On the other hand, laparatomy and laparoscopy have the highest rate of success in diagnosing TB with $100 \%$ and $94.5 \%$ cases being confirmed respectively although this imposes its own risk given its invasive nature and higher cost [70]. Lastly, a therapeutic trial of anti-TB treatment has shown to be effective in diagnosing and treating tuberculous infections in endemic areas like in Malaysian setting [77].

Majority of tuberculous colitis patients have responded to anti-tuberculosis treatment and delay in treatment imposes higher mortality and morbidity rate [59] [78]. Common diagnostic and management dilemma in tuberculosis colitis is given its nature of clinical presentation that usually mimics Crohns' disease and carcinoma of the colon [59] [75]-[78]. Although there are risks of falsely labeling a patient with tuberculous colitis given that anti-inflammatory properties of anti-tuberculosis treatment may resolve lesions in inflammatory bowel disease patient, study has shown that this is not a common occurrence [59] [74]. Besides that, starting anti-tuberculosis treatment in inflammatory bowel disease or malignancy of the bowel does not confer adverse effects as it does by starting immunosuppressive chemotherapy in patients with underlying tuberculosis where it leads to dissemination of the tuberculosis [59]. This is especially important clinically in areas with higher prevalence of tuberculosis as compared to inflammatory bowel disease or malignancy of the bowel. Thus, it is worthwhile to treat patient with anti-tuberculous treatment based on a high clinical suspicion given that tuberculosis is curable provided appropriate treatment is implemented. In addition, endoscopy post anti-tuberculosis treatment in 69 patients with tuberculous colitis has shown close to $100 \%$ improvement of the lesions [59]. This had led to the clinical implication that does not require repeated endoscopy in order to monitor anti-tuberculous treatment response in patients with tuberculous colitis provided their clinical symptom improves [59]. 


\subsection{Tuberculous Cervical Lymphadenitis}

Tuberculous lymphadenitis makes up 35\% of the extra pulmonary tuberculosis incidence worldwide out of which cervical lymph node is the commonest site of infection, which makes up $60 \%$ - 90\% of the cases [79] [80]. This incidence is higher among HIV positive patients as they make up $53 \%-62 \%$ of the extra-pulmonary tuberculosis cases [81] [82]. Tuberculous lymphadenitis is usually more common among African Americans and Asians, particularly in their second decade although tuberculous lymphadenitis can occur across any age group [82] [83]. Many studies have established a tendency in female patients [82] [83]. The commonest cause of tuberculous lymphadenitis is Mycobacterium Tuberculosis whereas non-tuberculous lymphadenitis is often caused by Mycobacterium Avium-Intracellular complex [79].

Tuberculous lymphadenitis may occur as a primary infection or as a result of reactivation of a dormant foci as well as a direct entry from a contagious focus [79]. In primary infection, the inhaled droplet nuclei are small enough to pass across muco-ciliary defenses in bronchi and lodge in the terminal lung alveoli [79]. The bacilli that multiply in the Ghon focus of the lungs would then be drained by lymphatic drainage into the hilar lymph nodes and thus forming the primary complex [84]. Hilar, mediastinal and paratracheal lymph nodes are the primary regional lymph nodes that would be infected from where the lymphatic drainage can spread into any part of the lymphatic system [84]. Cervical tuberculous lymphadenitis being the commonest site of infection occurs when the bacilli from the primary focus spread into tonsils, adenoid sinusoids and osteomyelitis of ethmoid bones [85] [86]. Initially, progressive multiplication of the bacilli will be followed by delayed hypersensitivity reaction where there will be marked hyperemia, swelling, necrosis and caseation of the centre of the lymph node [85] [86]. Progressive inflammation will lead to further swelling and mothing of several nodes where adhesion to adjacent skin may cause induration and purple discoloration [86] [87].

Tuberculous cervical lymphadenitis may present as unilateral, single or multiple mass or masses commonly at the posterior cervical margin which is usually a non-tender slow growing mass over weeks to months [88] [89]. Up to $10 \%$ of patients may present with fistula formation [90] [91]. Besides that, $21.8 \%$ of tuberculous lymphadenitis patients have presented with a history of previous tuberculosis patient contact whereas as high as $16.1 \%$ of patients have had previous tuberculosis infection [91] [92]. Studies have shown that tuberculous lymphadenitis would also present with systemic symptoms commonly low grade fever, weight loss, fatigue and less commonly night sweats although cough is rather not prominent [92] [93]. However, 57\% of patients may not present with any systemic symptoms [87] [92] [93]. In addition, multiplicity, caseation and matting are some of the diagnostic features in tuberculous lymph node [79]. It is also important to note that the patient may present with tender lymph node swelling if there is a secondary bacterial infection, in a rapidly growing mass as well as in if they are HIV positive [87]. The features of the lymph node may vary according to the stages as explained in Figure 1 based on Jones and Campbell criteria [94].

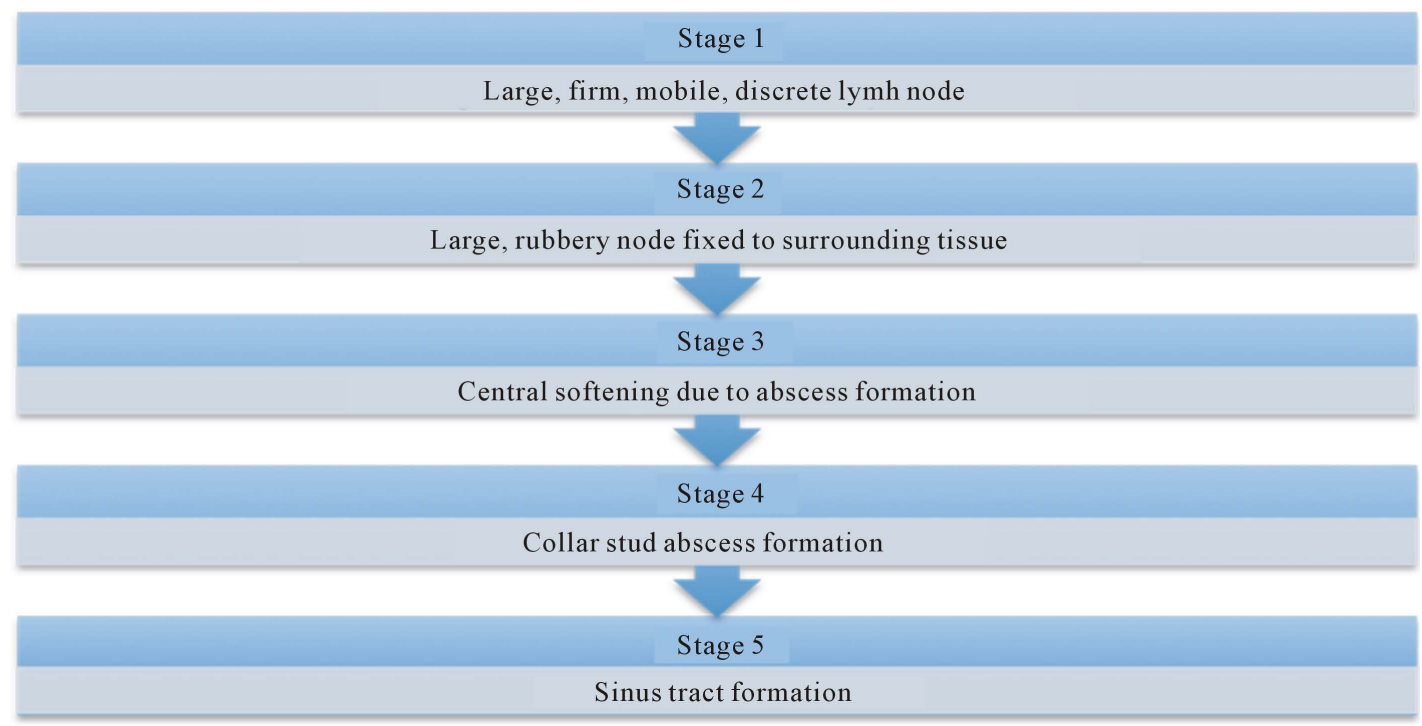

Figure 1. Jones and Campbell description on stages of tuberculous Imphadenitis [94]. 
When it comes to diagnosing and treating cervical tuberculous lymphadenitis, a very high suspicion index is required as the differential diagnosis is extensive [95] [96]. This includes various infections, neoplasms, nonspecific reactive hyperplasia, sarcoidosis, toxoplasmosis, collagen vascular disease, cat-scratch fever and reticuloendothelial disease [95] [96]. A study in United Kingdom has established an algorithm to diagnose and manage tuberculous cervical lymphadenitis [97].

Patients presenting with enlarged lymph node should be investigated with tuberculin skin test, fine needle aspiration (FNA) of the lymph node , HIV screening text and a chest X-Ray if they have risk factors of developing tuberculosis [97]. Patients with FNA results consistent with tuberculosis should be started on anti-tuberculous treatment while waiting for the culture result [97]. If patients show no improvement upon commencement of treatment and culture results are negative, these patients could be followed up with an excisional biopsy after anti-tuberculous treatment is either completed or an alternative diagnosis is considered based on the biopsy results [97].

However, if the first line investigations are inconclusive or if a patient is immunocompromised, they should be further investigated with excisional biopsy to assist in the diagnosis [97]. Anti-tuberculous treatment can be started if findings are consistent with tuberculosis while culture results are still pending [97]. Clinical response, positive culture and/or emergence of new enlarged lymph node warrants repeat FNA, cytology and culture [97]. If patients have enlarged lymph node post anti-tuberculous treatment, these patients require short-term observation where a repeated diagnostic and treatment measures should be implemented where it is necessary [97].

\section{Conclusion}

EPTB has various forms of clinical manifestation, which imposes diagnostic and treatment challenges. Thus, it is crucial to always include tuberculosis as part of working diagnosis especially in regions where tuberculosis is endemic until proven otherwise. Hence it is imperative to start treatment early to ensure better response.

\section{Conflict of Interests}

The authors have no conflict of interests.

\section{Informed Consent}

Informed consent was obtained from the three patients prior to publication of this report.

\section{Ethical Approval}

Ethical approval was obtained from the relevant authority.

\section{References}

[1] World Health Organization (2013) Global Tuberculosis Report 2013: World Health Organization. Geneva.

[2] Gomes, T., Vinhas, S.A., Reis-Santos, B., Palaci, A., Peres, R.L., Aguiar, P.P., et al. (2013) Extrapulmonary Tuberculosis: Mycobacterium Tuberculosis Strains and Host Risk Factors in a Large Urban Setting in Brazil. PloS One, 8, e74517. http://dx.doi.org/10.1371/journal.pone.0074517

[3] Solovic, I., Jonsson, J., Korzeniewska-Koseła, M., Chiotan, D.I., Pace-Asciak, A., Slump, E., Rumetshofer, R., Abubakar, I., Kos, S., Svetina-Sorli, P., Haas, W., Bauer, T., Sandgren, A. and van der Werf, M.J. (2011) Challenges in Diagnosing Extrapulmonary Tuberculosis in the European Union. Euro Surveilliance, 18, pii: 20432.

[4] Beek, L.A., van der Werf, M.J., Richter, C. and Borgdorff, M.W. (2006) Extrapulmonary Tuberculosis by Nationality, The Netherlands, 1993-2001. Emerging Infectious Diseases, 12, 1375-1382. http://dx.doi.org/10.3201/eid1209.050553

[5] Yang, Z., Kong, Y., Wilson, F., Foxman, B., Fowler, A.H., Marrs, C.F., et al. (2004) Identification of Risk Factors for Extrapulmonary Tuberculosis. Clinical Infectious Diseases, 38, 199-205. http://dx.doi.org/10.1086/380644

[6] Fiske, C.T., Griffin, M.R., Erin, H., Warkentin, J., Lisa, K., Arbogast, P.G., et al. (2010) Black Race, Sex, and Extrapulmonary Tuberculosis Risk: An Observational Study. BMC Infectious Diseases, 10, 16. http://dx.doi.org/10.1186/1471-2334-10-16

[7] Al-Otaibi, A., Almuneef, M. and Hameed, T. (2012) An Unusual Combination of Extrapulmonary Manifestations of Tuberculosis in a Child. Journal of Infection and Public Health, 5, 203-206.

http://dx.doi.org/10.1016/j.jiph.2011.11.005 
[8] Markowski, J., Witkowska, M., Gierek, T., Pasternak, K., Ciupińska-Kajor, M., Kajor, M., et al. (2011) Head and Neck Tuberculosis-Still Current Problem in ENT Practice. Otolaryngologia Polska, 65, 272-275. (In Polish) http://dx.doi.org/10.1016/S0030-6657(11)70689-8

[9] Farah, M.G., Rygh, J.H., Steen, T.W., Selmer, R., Heldal, E. and Bjune, G. (2006) Patient and Health Care System Delays in the Start of Tuberculosis Treatment in Norway. BMC Infectious Diseases, 6, 33. http://dx.doi.org/10.1186/1471-2334-6-33

[10] Siebert, A.F., Haynes Jr., J., Middleton, R., et al. (1991) Tuberculous Pleural Effusion: Twenty-Year Experience. Chest, 99, 883-886 http://dx.doi.org/10.1378/chest.99.4.883

[11] Reider, H.L., Snider Jr., D.E. and Cauthen, G.M. (1990) Extra Pulmonary Tuberculosis in the United States. American Review of Respiratory Disease, 141, 347-351, 579.

[12] Vidal, R., de Garcia, J., Ruiz, J., et al. (1986) Estudio Controlado de 637 Pacientes con tuberculosis: Diagnostico y resultados tera-pe uticoscon esquemas de 9 y 6 meses. Medicina Clínica (Barc), 87, 368-370.

[13] Stead, W.W., Eichenholz, A. and Staus, H.-K. (1955) Operative and Patho-Logic Findings in Twenty-Four Patients with Syndrome of Idiopathic Pleurisy with Effusion, Presumably Tuberculous. American Review of Respiratory Disease, 71, 473-502.

[14] Barnes, P.F., Mistry, S.D., Cooper, C.L., et al. (1989) Compartmentalization of a CD4 T Lymphocyte Subpopulation in Tuberculous Pleuritis. The Journal of Immunology, 142, 1114-1119.

[15] Moudgil, H., Sridhar, G. and Leitch, A.G. (1994) Reactivation Disease: The Commonest Form of Tuberculous Pleural Effusion in Edinburgh, 1980-1991. Respiratory Medicine, 88, 301-304. http://dx.doi.org/10.1016/0954-6111(94)90060-4

[16] Light, R.W. (1998) Establishing the Diagnosis of Tuberculous Pleuritis. Archives of Internal Medicine, 158, $1967-1968$. http://dx.doi.org/10.1001/archinte.158.18.1967

[17] Light, R.W. (2001) Tuberculous Pleural Effusions. In: Light, R.W., Ed., Pleural Diseases, Williams and Wilkins, Philadelphia, 100.

[18] Wang, N.S. (1975) The Preformed Stomas Connecting the Pleural Cavity and the Lymphatics in the Parietal Pleura. American Review of Respiratory Disease, 111, 12-20.

[19] Levine, H., Szanto, P.B. and Cugell, D.W. (1968) Tuberculosis Pleurisy: An Acute Illness. Archives of Internal Medicine, 122, 329-332. http://dx.doi.org/10.1001/archinte.1968.00300090039009

[20] Berger, H.W. and Mejra, E. (1973) Tuberculous Pleurisy. Chest, 63, 88-92. http://dx.doi.org/10.1378/chest.63.1.88

[21] Aho, K., Brander, E. and Patiala, J. (1968) Studies for Primary Drug Resistance in Tuberculosis Pleurisy. Scandinavian Journal of Respiratory Diseases, 63S, 111-114.

[22] Epstein, D.M., Kline, L.R., Albelda, S.M. and Miller, W.T. (1987) Tuberculosis Pleural Effusions. Chest, 91, $106-109$. http://dx.doi.org/10.1378/chest.91.1.106

[23] Gopi, A., Madhavan, S., Sharma, S. and Sahn, S. (2007) Diagnosis and Treatment of Tuberculous Pleural Effusion in 2006. Chest, 131, 880-889. http://dx.doi.org/10.1378/chest.06-2063

[24] Ferrer, J.S. (1996) Pleural Tuberculosis: Incidence, Pathogenesis, Diagnosis and Treatment. Current Opinion in Pulmonary Medicine, 2, 327-334.

[25] Jones, B.E., Young, S.M.M., Antoniskis, D., et al. (1993) Relationship of the Manifestations of TB to CD4 Cell Counts in Patients with Human Immunodeficiency Virus Infection. American Review of Respiratory Disease, 148, 1292-1297. http://dx.doi.org/10.1164/ajrccm/148.5.1292

[26] Richter, C., Perenborn, R., Mtoni, I., et al. (1994) Clinical Features of HIV-Seropositive and HIV-Seronegative Patients with Tuberculous Pleural Effusions in Dar es Sabam, Tanzania. Chest, 106, 1471-1475. http://dx.doi.org/10.1378/chest.106.5.1471

[27] Roper, W.H. and Waring, J.J. (1955) Primary Serofibrinous Pleural Effusion in Military Personnel. American Review of Tuberculosis, 71, 616-634.

[28] Khan, A.H., Sulaiman, S.A.S., Muttalif, A.R., Hassali, M.A., Akram, H., Gillani, S.W., et al. (2013) Pleural Tuberculosis and Its Treatment Outcomes. Tropical Journal of Pharmaceutical Research, 12, 623-627. http://dx.doi.org/10.4314/tjpr.v12i4.27

[29] Yam, L.T. (1967) Diagnostic Significance of Lymphocytes in Pleural Effusions. Annals of Internal Medicine, 66, $972-$ 982. http://dx.doi.org/10.7326/0003-4819-66-5-972

[30] Light, R.W., Erozan, Y.S. and Ball, W.C. (1973) Cells in Pleural Fluid: Their Value in Differential Diagnosis. Archives of Internal Medicine, 132, 854-860. http://dx.doi.org/10.1001/archinte.1973.03650120060011

[31] Spriggs, A.I. and Boddington, M.M. (1968) The Cytology of Effusions. 2nd Edition, Grune \& Stratton, New York. 
[32] Kalomenidis, I. and Light, R.W. (2003) Eosinophilic Pleural Effusions. Current Opinion in Pulmonary Medicine, 9, 254-260. http://dx.doi.org/10.1097/00063198-200307000-00002

[33] Light, R. (2010) Update on Tuberculous Pleural Effusion. Respirology, 15, 451-458. http://dx.doi.org/10.1111/j.1440-1843.2010.01723.x

[34] Villena, V., Lopez-Encuentra, A., Pozo, F., et al. (2003) Interferon Gamma Levels in Pleural Fluid for the Diagnosis of Tuberculosis. American Journal of Medicine, 115, 365-370. http://dx.doi.org/10.1016/S0002-9343(03)00423-6

[35] Sharma, S.K. and Banga, A. (2005) Pleural Fluid Interferon-Gamma and Adenosine Deaminase Levels in Tuberculosis Pleural Effusion: A Cost-Effectiveness Analysis. Journal of Clinical Laboratory Analysis, 19, 40-46.

[36] Conde, M.B., Loivos, A.C., Rezende, V.M., et al. (2003) Yield of Sputum Induction in the Diagnosis of Pleural Tuberculosis. American Journal of Respiratory and Critical Care Medicine, 167, 723-725. http://dx.doi.org/10.1164/rccm.2111019

[37] Valdes, L., Alvarez, D., San Jose, E., et al. (1998) Tuberculous Pleurisy: A Study of 254 Patients. Archives of Internal Medicine, 158, 2017-2021. http://dx.doi.org/10.1001/archinte.158.18.2017

[38] Luzze, H., Elliott, A.M., Joloba, M.L., et al. (2001) Evaluation of Suspected Tuberculous Pleurisy: Clinical and Diagnostic Findings in HIV-1-Positive and HIV-Negative Adults in Uganda. International Journal of Tuberculosis and Lung Disease, 5, 746-753.

[39] Light, R.W. (2007) Pleural Diseases. 5th Edition, Lippincott, Williams \& Wilkins, Baltimore.

[40] Wong, P. (2005) Management of Tuberculous Pleuritis: Can We Do Better? Respirology, 10, 144-148. http://dx.doi.org/10.1111/j.1440-1843.2005.00689.x

[41] Ormerod, L.P., McCarthy, O.R., Rudd, R.M. and Horsfield, N. (1995) Short-Course Chemotherapy for Tuberculous Pleural Effusion and Culture-Negative Pulmonary Tuberculosis. Tubercle and Lung Disease, 76, 25-27. http://dx.doi.org/10.1016/0962-8479(95)90575-8

[42] Joint Tuberculosis Committee of the British Thoracic Society (1998) Chemotherapy and Management of Tuberculosis in the United Kingdom: Recommendations 1998. Thorax, 53, 536-548. http://dx.doi.org/10.1136/thx.53.7.536

[43] Barbas, C.S., Cukier, A., de Varvalho, C.R.R., Filho, J.V.B. and Light, R.W. (1991) The Relationship between Pleural Fluid Findings and the Development of Pleural Thickening in Patients with Pleural Tuberculosis. Chest, 100, 12641267. http://dx.doi.org/10.1378/chest.100.5.1264

[44] Kwak, S.M., Park, C.S., Cho, J.H., et al. (2004) The Effects of Urokinase Instillation Therapy via Percutaneous Transthoracic Catheter in Loculated Tuberculous Pleural Effusion: A Randomized Prospective Study. Yonsei Medical Journal, 45, 822-828. http://dx.doi.org/10.3349/ymj.2004.45.5.822

[45] Hiraoka, K., Nagata, N., Kawajiri, T., et al. (1998) Paradoxical Pleural Response to Antituberculous Chemotherapy and Isoniazid-Induced Lupus. Review and Report of Two Cases. Respiration, 65, 152-155. http://dx.doi.org/10.1159/000029251

[46] Choi, Y.W., Jeon, S.C., Seo, H.S., et al. (2002) Tuberculous Pleural Effusion: New Pulmonary Lesions during Treatment. Radiology, 224, 493-502. http://dx.doi.org/10.1148/radiol.2242011280

[47] Galarza, I., Canete, C., Granados, A., Estopa, R. and Manresa, F. (1995) Randomised Trial of Corticosteroids in the Treatment of Tuberculous Pleurisy. Thorax, 50, 1305-1307. http://dx.doi.org/10.1136/thx.50.12.1305

[48] Large, S.E. and Levick, R.K. (1958) Aspiration in the Treatment of Primary Tuberculous Pleural Effusion. British Medical Journal, 30, 1512-1514. http://dx.doi.org/10.1136/bmj.1.5086.1512

[49] Wong, L.-M. and Calderwood, S. (2016) Tuberculous Enteritis. http://www.uptodate.com/contents/tuberculous-enteritis

[50] Guth, A.A. and Kim, U. (1991) The Reappearance of Abdominal Tuberculosis. Surgery Gynecology \& Obstetrics, 172, 432-436.

[51] Boudiaf, M., Zidi, S.H., Soyer, P., Lavergne-Slove, A., Kardache, M., Logeay, O. and Rymer, R., (1998) Tuberculous Colitis Mimicking Crohn's Disease: Utility of Computed Tomography in the Differentiation. European Radiology, 8, 1221-1223. http://dx.doi.org/10.1007/s003300050539

[52] Carrera, G.F., Young, S. and Lewicki, A.M. (1976) Intestinal Tuberculosis. Gastrointestinal Radiology, 1, 147-155. http://dx.doi.org/10.1007/BF02256357

[53] Chatzicostas, C., Koutroubakis, I.E., Maria, T., Maria, R., Panagiotis, P. and Elias, A.K. (2002) Colonic Tuberculosis Mimicking Crohn's Disease: Case Report. BMC Gastroenterology, 2, 10.

[54] Watson, J.M. and Gill, O.N. (1990) HIV Infection and Tuberculosis. British Medical Journal, 300, 63. http://dx.doi.org/10.1136/bmj.300.6717.63

[55] Barral, M., Boudiaf, M., Dohan, A., Hoeffel, C., Camus, M., Pautrat, K., Fishman, E.K., Cohen, S. and Soyer, P., (2015) MDCT of Acute Colitis in Adults: An Update in Current Imaging Features. Diagnostic and Interventional Im- 
aging, 96, 133-149. http://dx.doi.org/10.1016/j.diii.2014.04.008

[56] Donoghue, H.D. and Holton, J. (2009) Intestinal Tuberculosis. Current Opinion in Infectious Diseases, 22, $490-496$. http://dx.doi.org/10.1097/QCO.0b013e3283306712

[57] Braun, M.M., Cote, T.R. and Rabkin, C.S. (1993) Trends in Death with Tuberculosis during the AIDS Era. The Journal of the American Medical Association, 269, 2865-2868. http://dx.doi.org/10.1001/jama.1993.03500220051025

[58] Delabrousse, E., Ferreira, F., Badet, N., Martin, M. and Zins, M. (2013) Coping with the Problems of Diagnosis of Acute Colitis. Diagnostic and Interventional Imaging, 94, 793-804. http://dx.doi.org/10.1016/j.diii.2013.03.012

[59] Mukewar, S., Mukewar, S., Ravi, R., Prasad, A. and Dua, K.S. (2012) Colon Tuberculosis: Endoscopic Features and Prospective Endoscopic Follow-Up after Anti-Tuberculosis Treatment. Clinical and Translational Gastroenterology, 3, e24. http://dx.doi.org/10.1038/ctg.2012.19

[60] Brenner, S.M., Anne, G. and Parker, J.G. (1970) Tuberculous Colitis Simulating Nonspecific Granulomatous Disease of the Colon. American Journal of Digestive Diseases, 15, 85-92. http://dx.doi.org/10.1007/BF02239351

[61] Horvath, K.D. and Whelan, R.L. (1998) Intestinal Tuberculosis: Return of an Old Disease. The American Journal of Gastroenterology, 93, 692-696. http://dx.doi.org/10.1111/j.1572-0241.1998.207_a.X

[62] Alvares, J.F., Devarbhavi, H., Makhija, P., Rao, S. and Kottoor, R. (2005) Clinical, Colonoscopic, and Histological Profile of Colonic Tuberculosis in a Tertiary Hospital. Endoscopy, 37, 351-356. http://dx.doi.org/10.1055/s-2005-861116

[63] Das, H.S., Rathi, P., Sawant, P. et al. (2000) Colonic Tuberculosis: Colonoscopic Appearance and Clinico-Pathologic Analysis. Journal of the Association of Physicians of India, 48, 708-710.

[64] Sáenz, E.V., Magro, P.M.H., Fernando Álvarez-Tostado Fernández, J. and Ovalle, M.V. (2002) Colonic Tuberculosis. Digestive Diseases and Sciences, 47, 2045-2048. http://dx.doi.org/10.1023/A:1019624913037

[65] Misra, S.P., Misra, V., Dwivedi, M., Arora, J.S. and Kunwar, B.K. (2004) Tuberculous Colonic Strictures: Impact of Dilation on Diagnosis. Endoscopy, 36, 1099-1103. http://dx.doi.org/10.1055/s-2004-826046

[66] Chong, V.H. and Lim, K.S. (2009) Gastrointestinal Tuberculosis. Singapore Medical Journal, 50, 638-645 (quiz 646).

[67] Palmer, K.R., Patil, D.H., Basran, G.S., Riordan, J.F. and Silk, D.B. (1985) Abdominal Tuberculosis in Urban Britain—A Common Disease. Gut, 26, 1296-1305. http://dx.doi.org/10.1136/gut.26.12.1296

[68] Nagi, B., Kochhar, R., Bhasin, D.K. and Singh, K. (2003) Colorectal Tuberculosis. European Radiology, 13, 19071912. http://dx.doi.org/10.1007/s00330-002-1409-z

[69] Marshall, J.B. (1993) Tuberculosis of the Gastrointestinal Tract and Peritoneum. The American Journal of Gastroenterology, 88, 989-999.

[70] Ramesh, J., Banait, G.S. and Ormerod, L.P. (2008) Abdominal Tuberculosis in a District General Hospital: A Retrospective Review of 86 Cases. QJM: An International Journal of Medicine, 101, 189-195. http://dx.doi.org/10.1093/qjmed/hcm125

[71] Han, J.K., Kim, S.H., Choi, B.I., Yeon, K.M. and Han, M.C. (1996) Tuberculous Colitis Findings at Double-Contrast Barium Enema Examination. Diseases of the Colon \& Rectum, 39, 1204-1209. http://dx.doi.org/10.1007/BF02055109

[72] Brombart, M. and Massion, J. (1961) Radiologic Differences between Ileocecal Tuberculosis and Crohn's Disease. The American Journal of Digestive Diseases, 6, 589-603. http://dx.doi.org/10.1007/BF02232333

[73] Rosengart, T.K. and Coppa, G.F. (1990) Abdominal Mycobacterial Infections in Immunocompromised Patients. The American Journal of Surgery, 159, 125-130. http://dx.doi.org/10.1016/S0002-9610(05)80617-8

[74] Park, Y.S., Jun, D.W., Kim, S.H., et al. (2008) Colonoscopy Evaluation after Short-Term Anti-Tuberculosis Treatment in Nonspecific Ulcers on the Ileocecal Area. World Journal of Gastroenterology, 14, 5051-5058. http://dx.doi.org/10.3748/wjg.14.5051

[75] Bhargava, D.K., Shriniwas, Chawla, T.C., Tandon, B.N. and Kapur, B.M. (1985) Intestinal Tuberculosis: Bacteriological Study of Tissue Obtained by Colonoscopy and during Surgery. The Journal of Tropical Medicine and Hygiene, 88, 249-252.

[76] Bhargava, D.K. and Tandon, H.D. (1980) Ileocaecal Tuberculosis Diagnosed by Colonoscopy and Biopsy. Australian and New Zealand Journal of Surgery, 50, 583-585. http://dx.doi.org/10.1111/j.1445-2197.1980.tb04201.x

[77] Park, S.J., Han, J.K., Kim, T.K., Kim, J.S., Jung, H.C., Song, I.S. and Choi, B.I. (2000) Tuberculous Colitis Radiologic-Colonoscopic Correlation. American Journal of Roentgenology, 175, 121-128.

[78] BMJ (2016) Extrapumonary Tuberculosis. http://bestpractice.bmj.com.ezproxy.lib.monash.edu.au/best-practice/monograph/166/diagnosis/step-by-step.html

[79] Raghab, M.P. and Kumar J.A. (2009) Tuberculous Lymphadenitis. The Journal of the Association of Physicians of India, 57, 585-588. 
[80] Cantrell, R.W., Jensen, J.H. and Reid, D. (1975) Diagnosis and Management of Tuberculous Cervical Adenitis. Archives of Otolaryngology, 101, 53-57. http://dx.doi.org/10.1001/archotol.1975.00780300057016

[81] (2005) Global Tuberculosis Control: Surveillance, Planning, Financing. WHO Report, World Health Organization, Geneva.

[82] Sharma, S.K. and Mohan, A. (2004) Extrapulmonary Tuberculosis. Indian Journal of Medical Research, 120, 316-353

[83] Enarson, D.A., Ashley, M.J., Grzybowski, S., Ostapkowicz, E. and Dorken, E. (1980) Non-Respiratory Tuberculosis in Canada. Epidemiologic and Bacteriologic Features. American Journal of Epidemiology, 112, 341-351.

[84] Kent, D.C. (1967) Tuberculous Lymphadenitis: Not a Localized Disease Process. The American Journal of the Medical Sciences, 254, 866-874. http://dx.doi.org/10.1097/00000441-196712000-00016

[85] Shriner, K.A., Mathisen, G.E. and Goetz, M.B. (1992) Comparison of Mycobacterial Lymphadenitis among Persons Infected with Human Immunodeficiency Virus and Seronegative Controls. Clinical Infectious Diseases, 15, 601-605. http://dx.doi.org/10.1093/clind/15.4.601

[86] Dandapat, M.C., Mishra, B.M., Dash, S.P. and Kar, P.K. (1990) Peripheral Lymph Node Tuberculosis: A Review of 80 Cases. British Journal of Surgery, 77, 911-912. http://dx.doi.org/10.1002/bjs.1800770823

[87] Jha, B.C., Dass, A., Nagarkar, N.M., Gupta, R. and Singhal, S. (2001) Cervical Tuberculous Lymphadenopathy: Changing Clinical Pattern and Concepts in Management. Postgraduate Medical Journal, 77, 185-187. http://dx.doi.org/10.1136/pmj.77.905.185

[88] Kanlikama, M., Mumbuc, S., Bayazit, Y. and Sirikci, A. (2000) Management Strategy of Mycobacterial Cervical Lymphadenitis. The Journal of Laryngology \& Otology, 114, 274-278. http://dx.doi.org/10.1258/0022215001905544

[89] Penfold, C.N. and Revington, P.J. (1996) A Review of 23 Patients with Tuberculosis of the Head and Neck. British Journal of Oral and Maxillofacial Surgery, 34, 508-510. http://dx.doi.org/10.1016/S0266-4356(96)90246-6

[90] Dhooge, I., Dhooge, C., De Baets, F. and Van Cauwenberge, P. (1993) Diagnostic and Therapeutic Management of Atypical Mycobacterial Infections in Children. European Archives of Oto-Rhino-Laryngology, 250, 387-391. http://dx.doi.org/10.1007/BF00180382

[91] Danielides, V., Patrikakos, G., Moerman, M., Bonte, K., Dhooge, C. and Vermeersch, H. (2002) Diagnosis, Management and Surgical Treatment of Non-Tuberculous Mycobacterial Head and Neck Infection in Children. ORL: Journal for Oto-Rhino-Laryngology and Its Related Specialties, 64, 284-289. http://dx.doi.org/10.1159/000064138

[92] Lee, K.C., Tami, T.A., Lalwani, A.K. and Schecter, G. (1992) Contemporary Management of Cervical Tuberculosis. The Laryngoscope, 102, 60-64. http://dx.doi.org/10.1288/00005537-199201000-00012

[93] Levin-Epstein, A.A. and Lucente, F.E. (1982) Scrofula-The Dangerous Masquerader. The Laryngoscope, 92, $938-943$. http://dx.doi.org/10.1288/00005537-198208000-00015

[94] Jones, P.G. and Campbell, P.E. (1962) Tuberculous Lymphadenitis in Childhood: The Significance of Anonymous Mycobacteria. British Journal of Surgery, 50, 302-314. http://dx.doi.org/10.1002/bjs.18005022112

[95] Ibekwe, A.O., al Shareef, Z. and al Kindy, S. (1997) Diagnostic Problems of Tuberculous Cervical Adenitis (Scrofula). American Journal of Otolaryngology, 18, 202-205. http://dx.doi.org/10.1016/S0196-0709(97)90083-1

[96] Albright, J.T. and Pransky, S.M. (2003) Mycobacterial Infections of the Head and Neck. Pediatric Clinics of North America, 50, 503-514. http://dx.doi.org/10.1016/S0031-3955(03)00024-5

[97] Polesky, A., Grove, W. and Bhatia, G. (2005) Peripheral Tuberculous Lymphadenitis Epidemiology, Diagnosis, Treatment, and Outcome. Medicine, 84, 350-362. 